\title{
Reflets
}

Revue ontaroise d'intervention sociale et communautaire

\section{Message à nos lectrices et à nos lecteurs}

\section{Richard Carrière}

Volume 13, numéro 1, 2007

La violence dans tous ses états

URI : https://id.erudit.org/iderudit/016809ar

DOI : https://doi.org/10.7202/016809ar

Aller au sommaire du numéro

Éditeur(s)

Reflets : Revue ontaroise d'intervention sociale et communautaire

ISSN

1203-4576 (imprimé)

1712-8498 (numérique)

Découvrir la revue

Citer ce document

Carrière, R. (2007). Message à nos lectrices et à nos lecteurs. Reflets, 13(1), 8-8.

https://doi.org/10.7202/016809ar

Tous droits réservés (C) Reflets : Revue ontaroise d'intervention sociale et communautaire, 2007

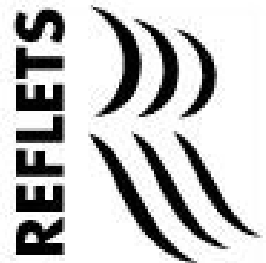

Ce document est protégé par la loi sur le droit d'auteur. L’utilisation des services d’Érudit (y compris la reproduction) est assujettie à sa politique d'utilisation que vous pouvez consulter en ligne.

https://apropos.erudit.org/fr/usagers/politique-dutilisation/ 


\section{Message à nos lectrices et à nos lecteurs}

Nous sommes heureux de vous présenter le volume 13 de Reflets.

Les plus fidèles parmi vous remarqueront dans le présent numéro une rubrique nouvelle à notre revue. Intitulée "Collaboration spéciale", elle vous propose un article provenant d'une autre source et qui vous serait difficilement accessible autrement. La présentation de tels textes ne sera qu'occasionnelle et ce sont les responsables de chacun des numéros qui en jugeront la pertinence. Ainsi, Myriam Bals, rédactrice de ce numéro, propose en primeur un extrait de Pink Blood - La violence homophobe au Canada qui sera publié sous peu. Nous remercions donc son auteur, Douglas Victor Janoff, ainsi que la maison d'éditions Triptyque, de nous avoir accordé la permission de reproduire un chapitre du livre, lequel s'inscrit parfaitement dans la thématique de ce numéro de Reflets, soit la violence sous toutes ses formes.

Par ailleurs, vous trouverez dans ce numéro la bibliographie de tous les articles parus dans les douze premiers volumes de Reflets, cela dans le but de les repérer plus aisément. Nous remercions Jeannine Turpin du travail minutieux de compilation et d'organisation qu'elle a consacré à cette bibliographie.3

Nous sommes aussi fiers de vous annoncer que la version intégrale de tous les numéros de Reflets sera bientôt disponible en ligne via le site du Consortium Érudit.Vous pourrez y accéder à l'adresse suivante : www.erudit.org

Cependant, l'abonnement à la revue permet l'accès aux plus récents numéros. Nous vous encourageons donc à vous abonner à Reflets et à inciter vos collègues à en faire autant.

Merci pour votre appui au fil des années. Bonne lecture!

Richard Carrière

Au nom du comité de direction de Reflets 